\title{
УДК 626.80 (571.621)
}

\section{ИЗМЕНЕНИЕ КОНЦЕНТРАЦИЙ ТЯЖЕЛЫХ МЕТАЛЛОВ В КОМПОНЕНТАХ МАЛОЙ РЕКИ (НА ПРИМЕРЕ ОСУШИТЕЛЬНОЙ МЕЛИОРАЦИИ)}

\author{
Зубарев Виталий Александрович, \\ Zubarev_1986@mail.ru \\ Институт комплексного анализа региональных проблем ДВО РАН, \\ Россия, 679016, г. Биробиджан, ул. Шолом-Алейхема, 4.
}

\begin{abstract}
Актуальность исследования заключается в необходимости оценки таких природных компонентов малой реки, как донные отложения и водные растения, которые способны аккумулировать различные поллютанты, поступающие с территории водосбора, и могут служить индикатором экологического состояния загрязнения воды в реке.

Цель: анализ изменения концентраций тяжелых металлов в компонентах малой реки (на примере осушительной мелиорации). объекты: поверхностные воды, донные отложения и водные растения, подверженные влиянию осушительной мелиорации. Методы: фильтрация проб воды через мембранные фильтры с диаметром пор 0,45 мкм для раздельного определения растворенной и взвешенной форм тяжелых металлов. Отбор проб донных отложений штанговым дночерпателем Гр-91 на глубине $25 \mathrm{~cm} \mathrm{от} \mathrm{поверхности} \mathrm{залегания.} \mathrm{Кислотное} \mathrm{разложение} \mathrm{проб} \mathrm{донных} \mathrm{отложений} \mathrm{и} \mathrm{растительности} \mathrm{в} \mathrm{микроволновой} \mathrm{системе}$ «Mars-6», измельчение в планетарной мельнице «Pulverisette 6», оnределение тяжельх металлов методом атомноабсорбционной спектрометрии на спектрометре «Solaar 6M».

Результаты. Под влиянием осушения в поверхностных водах происходит увеличение концентраций растворенных и взвешенных форм тяжелых металлов, в особенности $\mathrm{Fe}$ и $\mathrm{Pb}$, превышающих значения предельно-допустимых концентраций в 3 раза. В донных отложениях происходит накопление тяжелых металлов в 1,5-2 раза выше по отношению к верхнему течению реки, однако при изменении химических и гидрологических параметров среды металлы переходят опять в водоток, являясь источником вторичного загрязнения. Наиболее интенсивные процессы осаждения рассчитаны для $\mathrm{Fe}(\mathrm{IgK}$ распр $=5,06)$, $\mathrm{Pb}\left(\lg K_{\text {распр }}=4,76\right)$, а также для Zn (IgK распр $\left.=4,60\right)$. Средний характер седиментации прослеживается для Mn и Cu $\left(\lg K_{\text {распр }}=3,36\right)$. Для Ni коэфффициент имеет минимальное значение (IgKраспр $=2,82$ ), что говорит об обратных процессах миграции металла из донных отложений в воду. Осушительная мелиорация, меняя гидрохимические и гидрологические характеристики водотоков, приводит к увеличению концентраций тяжелых металлов в макрофритах в 2-3 раза.
\end{abstract}

\section{Ключевые слова:}

Среднеамурская низменность, малые реки, водная растительность, тяжелье металлы, донные отложения, осушительная мелиорация.

\section{Введение}

Территория Среднеамурской низменности характеризуется высокой переувлажненностью земель, что и обусловило необходимость проведения специальных агротехнических работ, так как избыточная обводненность почвенного покрова являлась большим тормозом в экономическом и социальном развитии региона [1]. Из-за переувлажнения земель землепользователи на почвах с нерегулярным водным режимом недобирали до 40 \% урожаев сельскохозяйственных культур. Эти причины предопределили широкомасштабное гидромелиоративное осушение переувлажненных земель. На начальном этапе (1930-1940 гг.) строительство мелиоративных систем проводилось почти без учета требований охраны природной среды, что оказало весьма ощутимое воздействие на окружающую среду.

Существующая в бассейне р. Амур сеть экологических наблюдений за состоянием малых водотоков фрагментарна и основным задачам мониторинга отвечает не полностью. Большая часть малых рек наблюдениями не охвачена.

Одно из наиболее существенных негативных влияний на компоненты экосистемы водотока (поверхностные воды, донные отложения, макрофиты) оказывают тяжелые металлы (ТМ). В группу наиболее распространенных ТМ, по мнению многих авторов, входят: $\mathrm{Fe}, \mathrm{Mn}, \mathrm{Cu}, \mathrm{Ni}, \mathrm{Zn}, \mathrm{Pb}$ и их соли [2]. Опас- ность в водной экосистеме усиливается тем, что ТМ не подвержены процессам разложения, а способны образовывать различные комплексные соединения, участвуют в гидролизе, процессе окислениявосстановления, а также могут мигрировать и аккумулироваться в различных компонентах водотока. Поэтому для экологической оценки водотоков, находящихся в условиях постоянного антропогенного прессинга, необходимо исследовать содержание различных ТМ в компонентах экосистем и изучать особенности их аккумуляции и миграции по компонентам реки [3]. Результаты таких исследований позволяют предложить более эффективные рекомендации для сохранения и устойчивого использования преобразованных малых рек.

Целью работы является оценка концентраций ТМ в компонентах малой реки Среднеамурской низменности под влиянием осушительной мелиорации.

\section{Материалы и методы исследования}

Объектом исследования послужила р. Солонечная, являющаяся водоприемником дренажных вод с осушительных мелиорационных систем [4], площадь преобразования ее бассейна осушительной мелиорацией составляет более $20 \%$.

Река Солонечная (рисунок) имеет площадь водо-

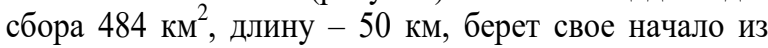
юго-западных склонов хребта Чурки, впадает в 
p. Амур. На всем протяжении река течет в глубокой заболоченной долине, в нее впадают множество осушительных каналов, соединенных между собой в единую сеть. В нижнем течении реки русло искусственно спрямлено. Глубина реки в среднем ее течении составляет 1,5-2 м, а ширина не более 5 м. В районе проведения осушительных работ течение слабо выражено, иногда не наблюдается вовсе. Бассейн р. Солонечная занят на 10 тыс. га сельскохозяйственными угодьями, в основном пашнями, пастбищами и улучшенными сенокосами, имеющими луговоболотный и лугово-глинистый тип почв, разнотравнолуговой и болотной растительностью [5].

На выбранном водотоке в период с 2009 по 2018 гг. производился отбор проб выше и ниже течения, а также в месте впадения осушительного канала в водоток. Выбор определенных точек отбора производился на основании предварительной гидрологической и гидрохимической рекогносцировки. Поверхностные воды отбирали в соответствии с ГОСТ 51592-2000 [6], донные отложения - по ГОСТ 17.1.5.01-80 [7]. В каждой точке отбор проб производился в трехкратной повторяемости. Общее количество проб поверхностных вод - 150, донных отложений - 150 , а водной растительности - 50 образцов. Отбор проб производился на середине реки.

Программа исследований включала оценку экологического состояния, поверхностных и донных отложений, гидробиологические исследования и статистическую обработку данных.

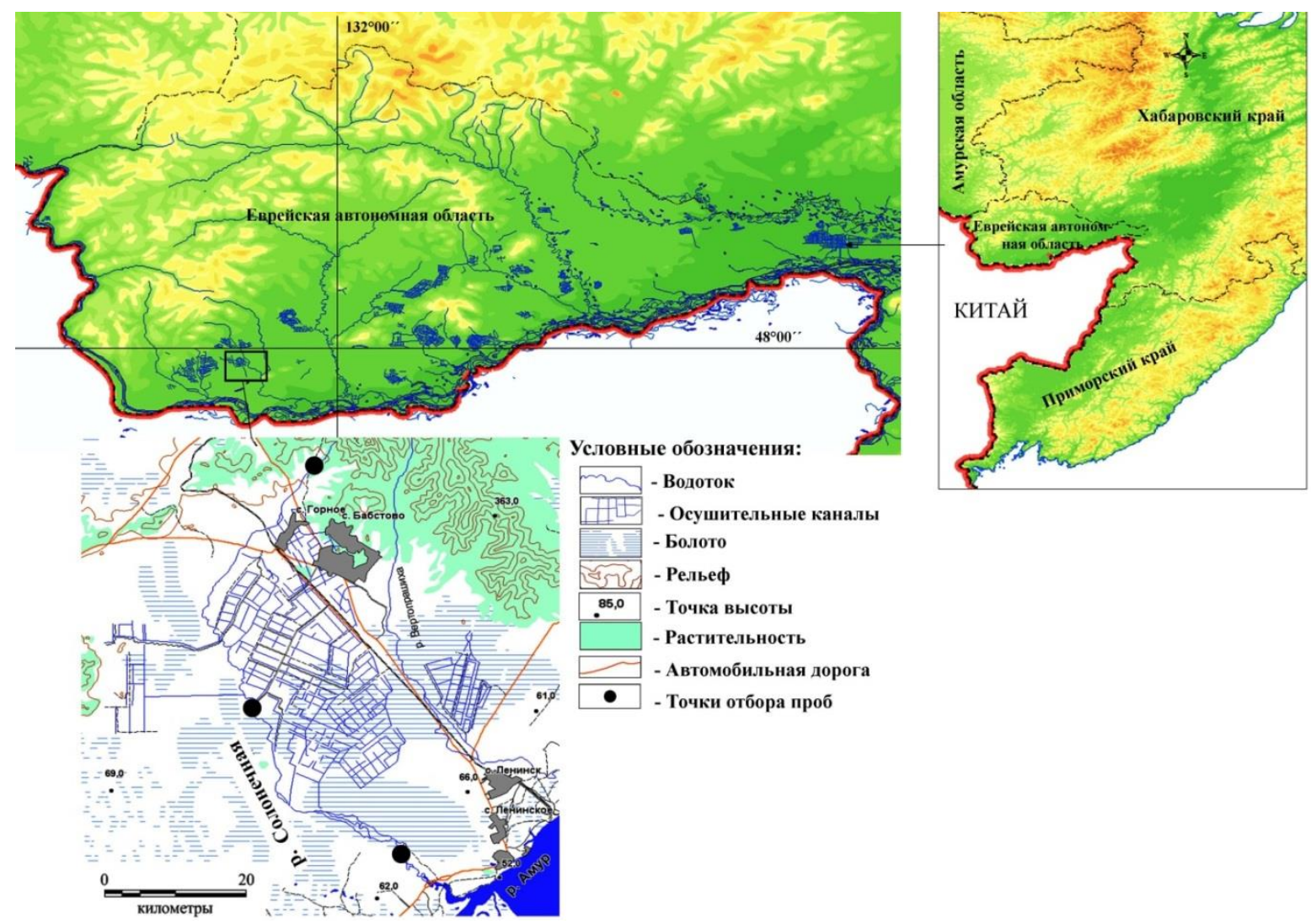

Рисунок. Расположение района исследования

Figure. Location of the study area

Для раздельного определения растворенной и взвешенной форм ТМ пробы воды фильтровались через мембранные фильтры с диаметром пор 0,45 мкм. Определение общего содержания ТМ в фильтрате требует предварительной процедуры деструкции ее связанных органических и неорганических форм и их перевода в аналитически определяемые формы. Разложение проб проводилось с использованием микроволновой системы «Mars-6», предназначенной для разложения объектов с органической и неорганической матрицами при подготовке проб к инструментальному анализу.

Пробы донных отложений отбирались штанговым дночерпателем Гр-91 на глубине 25 см от поверхности залегания. Пробы донных отложений помещались в предварительно подготовленные (очищенные $1 \mathrm{M} \mathrm{HCl}$ и промытые дистиллированной водой) полиэтиленовые контейнеры и хранились замороженными. В лаборатории образцы донных отложений высушивались при комнатной температуре в чистом помещении. Далее образцы донных отложений были отквартованы для получения средней пробы массой 50 г. Образцы в дальнейшем подвергались измельчению в планетарной мельнице «Pulverisette 6» до мелкой фракции $>1$ мкм. Масса измельченной пробы, которую использовали для анализа, составляла около 5 г. Для определения валового содержания ТМ все образцы донных отложений были подвержены кислотному разложению $\left(\mathrm{HNO}_{3} \mathrm{OCЧ}\right)$ в микроволновой системе «Mars-6». 
Для анализа транзита и аккумуляции тяжелых металлов из воды в донные отложения был применен коэффициент распределения [8-10]:

$$
\lg K_{\text {pacnp }}=\frac{\left[M_{\partial о}\right]}{\left[M_{\text {вода }}\right]},
$$

где $\lg \mathrm{K}_{\text {распр }}$ - коэффициент распределения; [ $\left.\mathrm{M}_{\text {до }}\right]$ содержание металла в донных отложениях, мг/кг; $\left[\mathrm{M}_{\text {вода }}\right]$ - содержание металла в воде, мг/дм³

Из макрофитов были выбраны растения семейства рдестовые: Potamogeton perfoliatus, относящиеся к группе погруженных укореняющихся гидрофитов $[11,12]$. Для определения валового содержания ТМ все образцы были подвержены кислотному разложению $\left(\mathrm{HNO}_{3} \mathrm{OCЧ}\right)$ в микроволновой системе «Mars-6».

Содержание растворенных (фильтрат речной воды) и взвешенных (осаждающиеся на фильтре) форм ТМ, а также валовых концентраций ТМ в донных отложениях и водной растительности определяли методом атомно-абсорбционной спектрометрии на приборе «ThermoElectron SOLAAR 6M». Все исследования проводили на лабораторной базе ИКАРП ДВО РАН, аналитик - Зубарев В.А.

\section{Результаты и их обсуждение}

Многочисленными исследованиями было показано, что ТМ при попадании в водоток превращаются в более токсичные формы по сравнению с исходными $[13,14]$, но в первую очередь нас интересовали растворимые формы как наиболее доступные для гидробионтов и регламентируемые в водоемах различного назначения. Оценка и анализ растворенных форм ТМ позволяет определить уровень загрязненности речной экосистемы, а также дает потенциал понять механизмы формирования состава воды и процессов, происходящих в водной среде $[15,16]$.

Таблица 1. Концентрации тяжельх металлов в воде

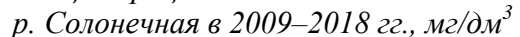

Table 1. Concentrations of heavy metals in the river Solnechnaya in 2009-2018, $\mathrm{mg} / \mathrm{dm}^{3}$

\begin{tabular}{|c|c|c|c|}
\hline $\begin{array}{c}\text { Тяжелые } \\
\text { металлы } \\
\text { Heavy metals }\end{array}$ & $\begin{array}{c}\text { Верхнее } \\
\text { течение } \\
\text { Upstream }\end{array}$ & $\begin{array}{c}\text { Осушительный } \\
\text { канал } \\
\text { Drainage channel }\end{array}$ & $\begin{array}{c}\text { Нижнее } \\
\text { течение } \\
\text { Downstream }\end{array}$ \\
\hline $\mathrm{Fe}$ & $\frac{0,6}{1,7}$ & $\frac{1,02}{6,8}$ & $\frac{0,8}{5,1}$ \\
\hline $\mathrm{Mn}$ & $\underline{0,03}$ & $\underline{0,15}$ & $\underline{0,09}$ \\
\hline $\mathrm{Pb}$ & $\underline{0,005}$ & $\underline{0,7}$ & $\underline{0,9}$ \\
\hline $\mathrm{Zn}$ & $\underline{0,02}$ & $\underline{0,04}$ & $\frac{0,03}{0,04}$ \\
\hline $\mathrm{Cu}$ & $\underline{0,01}$ & $\underline{0,03}$ & $\underline{0,05}$ \\
\hline $\mathrm{Ni}$ & $\underline{0,01}$ & $\underline{0,01}$ & $\underline{0,06}$ \\
\hline 0,00 & $\underline{0,01}$ & $\underline{0,02}$ \\
\hline
\end{tabular}

Примечание: Числитель - растворенная, знаменатель взвешенная форма.

Note: The numerator is the dissolved form, the denominator is the weighted form.

Железо является характерным элементом природных вод Среднеамурской низменности [17], что свя- зано главным образом с природными факторами, а также с особенностями формирования состава вод. Одной из причин повышенного содержания Fe в речных водах является широко распространенная заболоченность водосборных бассейнов Среднеамурской низменности [18]. ПДК Fе для речных вод составляет 0,3 мг/дм ${ }^{3}$. Во всех исследуемых образцах воды валовое железо на 70-80\% мигрирует во взвешенной форме, и около 20-30 \% приходится на растворенные формы. Наименьшее содержание Fe прослеживается в воде, отобранной в верхнем течении реки, при этом данная концентрация превышает значения ПДК в два раза. Наличие на территории области достаточно крупного железорудного района обусловило повышенное содержание железа в поверхностных водах. В месте впадения осушительного канала в водоток прослеживается увеличение концентраций растворенных форм Fe в 1,5 раза, а взвешенных форм в четыре раза. При проведении осушительных работ создаются условия улучшенной аэрации, что связанно с процессами выщелачивания из почв этого элемента из нижележащих горизонтов.

Марганеи, так же как и железо, является типоморфным элементом природных вод Среднеамурской низменности, его высокие концентрации связаны в основном с процессами выщелачивания железомарганцевых руд. ПДК Mn в поверхностных водах $0,1 \mathrm{мг} /$ дм $^{3}$. Минимальное содержание растворенной формы Mn обнаружено в верхнем течении реки 0,03 мг/дм ${ }^{3}$, что не превышает значений ПДК. Во всех исследуемых точках отбора проб Mn более чем на $80 \%$ находится во взвешенной форме. В месте впадения мелиоративного канала в водоток его концентрация возрастает в 6 раз за счет повышенного содержания органических веществ и преобладания в их составе взвешенных глинистых частиц [19]. В результате осаждения взвешенных веществ марганец способен накапливаться в донных отложениях в значительных количествах.

Цинк. Одним из источников поступления $\mathrm{Zn}$ в природные воды являются процессы разрушения и растворения горных пород и минералов, а также железных и сульфидных руд [20]. По результатам наших исследований в верхних течениях реки обнаружены самые низкие концентрации цинка, при этом примерно на $70 \%$ он представлен в растворенной форме и на 30 \% во взвешенной. В дренажных водах, поступающих с осушительных систем, его валовое содержание возросло в 5 раз, при этом на $80 \%$ Zn представлен во взвешенной форме и всего $20 \%$ приходится на растворенную форму.

Свинец относится к I классу опасности. ПДК свинца составляет 0,03 мг/дм³ ${ }^{3}$ В природных поверхностных водах свинец образует малорастворимые соединения, сравнительно легко вступая в реакции с различными соединениями в воде [21]. По результатам наших исследований в верхнем течении реки концентрация свинца мене $0,01 \mathrm{Mг} /$ дм $^{3}$. В точках отбора проб впадения осушительной системы в водоток содержание $\mathrm{Pb}$ становится 0,1 мг/дм ${ }^{3}$, что превышает значения ПДК в 3 раза. В данных точках отбора проб 
основной формой миграции является растворенная около $75 \%$, в виде минеральных и органоминеральных комплексов, а также простых ионов. В нижнем течении реки валовая концентрация $\mathrm{Pb}$ снижается, при этом на 60 \% он находится во взвешенной форме. Особенностью транзита-аккумуляции свинца в природных водах является процесс осаждения и комплексообразования с органическими лигандами [22].

Медь в поверхностных водах, в районе сельскохозяйственного производства, поступает со сточными водами при использовании пестицидов и фунгицидов (хлорокись меди, медный купорос, бордоская жидкость и др.) $[23,24]$. Валовая концентрация меди (растворенная и взвешенная форма) в поверхностных водах выше района проведения осушения равна $0,02 \mathrm{мг} /$ дм $^{3}, 50 \%$ представлено в растворенной и столько же во взвешенной форме. В месте впадения осушительного канала в водоток концентрация $\mathrm{Cu}$ по сравнению с фоном возрастает в 6 раз и равна $0,12 \mathrm{мг} /$ дм $^{3}$. Основной формой миграции становится взвешенная форма - 70 \%. В нижнем течении содержание меди снижается до 0,07 мг/дм ${ }^{3}$, при этом на $80 \%$ он

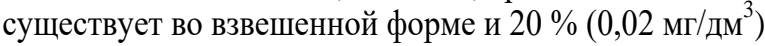
приходится на взвешенную форму.

Никель. Присутствие никеля в природной воде в значительной степени обусловлено составом пород, через которые проходит вода [25]. Во всех точках отбора проб на водотоке прослеживаются низкие концентрации никеля, что обусловлено сорбцией ионов, соосаждением его на гидроокиси железа.

Таким образом, сформировавшаяся ситуация на реке Солонечная, принимающей дренажные воды с сельскохозяйственных земель, представляет возможную экологическую опасность для водотока, о чем свидетельствует повышенное содержание ТМ в нижнем течении реки. Однако с точки зрения экологического мониторинга водного объекта важное значение имеют данные о содержании ТМ не только в воде, но и в донных отложениях, которые могут полноценно отражать экологическое состояние водоема и информировать о загрязнении вследствие антропогенной деятельности на водосборной территории [26].

Таблица 2. Концентрачии тяжелых металлов в донных отложениях р. Солонечная 2009-2018 г2., мг/кг

Table 2. Concentrations of heavy metals in the bottom sediments of the Solnechnaya river 2009-2018, $m g / k g$

\begin{tabular}{|c|c|c|c|}
\hline $\begin{array}{c}\text { Тяжелые } \\
\text { металлы } \\
\text { Heavy metals }\end{array}$ & $\begin{array}{c}\text { Верхнеe } \\
\text { течение } \\
\text { Upstream }\end{array}$ & $\begin{array}{c}\text { Осушительный } \\
\text { канал } \\
\text { Drainage channel }\end{array}$ & $\begin{array}{c}\text { Нижнее течение } \\
\text { Downstream }\end{array}$ \\
\hline $\mathrm{Fe}$ & $62229,8 \pm 202,3$ & $77158,8 \pm 203,3$ & $70610,0 \pm 164,6$ \\
\hline $\mathrm{Mn}$ & $608,9 \pm 8,4$ & $995,2 \pm 20,3$ & $896,2 \pm 10,1$ \\
\hline $\mathrm{Pb}$ & $87,2 \pm 6,1$ & $204,3 \pm 5,3$ & $186,6 \pm 6,9$ \\
\hline $\mathrm{Zn}$ & $18,4 \pm 1,3$ & $65,9 \pm 5,9$ & $59,7 \pm 5,2$ \\
\hline $\mathrm{Cu}$ & $21,1 \pm 3,8$ & $51,9 \pm 4,5$ & $49,5 \pm 2,5$ \\
\hline $\mathrm{Ni}$ & $21,6 \pm 0,6$ & $24,0 \pm 1,9$ & $23,7 \pm 1,4$ \\
\hline
\end{tabular}

Как видно из данных, приведенных в табл. 2, под влиянием мелиорации происходит накопление ТМ в донных отложениях, что может говорить об интенсивности влияния осушения на водоток. В период промывного типа водного режима 2013 г. наблюдается снижение концентраций $\mathrm{Pb}, \mathrm{Zn}$ и $\mathrm{Cu}$ вследствие выпадения большого количества атмосферных осадков. Для марганца и никеля прослеживается осаждение и, как следствие, увеличение концентраций этих элементов.

Для анализа процессов транзита-аккумуляции ТМ в системе «вода - донные отложения» нами был применен расчет коэффициента распределения $\lg \mathrm{K}_{\text {распр, }}$ который позволяет определить периоды максимального содержания ТМ в донных отложениях и дает потенциал прогнозирования исследуемых факторов на процессы перераспределения ТМ [27, 28].

По результатам проведенных исследований выяснилось, что при изменении рН воды в сторону слабощелочной реакции среды до 7,8 и снижении скорости течения воды и растворенного кислорода происходит осаждение ТМ в донные отложения. Наиболее интенсивные процессы осаждения рассчитаны для $\mathrm{Fe}\left(\lg \mathrm{K}_{\text {распр }}=5,06\right), \quad \mathrm{Pb} \quad\left(\lg \mathrm{K}_{\text {распр }}=4,76\right)$, а также для $\mathrm{Zn}\left(\lg \mathrm{K}_{\text {распр }}=4,60\right)$. Средний характер седиментации прослеживается для $\mathrm{Mn}$ и $\mathrm{Cu}\left(\lg \mathrm{K}_{\text {распр }}=3,36\right)$. Для $\mathrm{Ni}$ коэффициент имеет минимальное значение $\left(\lg K_{\text {распр }}=2,82\right)$, что говорит об обратных процессах миграции металла из донных отложений в воду.

Таким образом, под влиянием осушительной мелиорации происходит накопление концентрации ТМ в донных отложениях, по отношению к верхнему течению реки превышают концентрации ТМ в 2-4 раза. Следовательно, под влиянием стоков дренажных вод создаются условия для накопления ТМ в донных отложениях, однако при изменении различных параметров водотока ТМ из донных отложений опять могут попасть в воду, тем самым может резвиться ситуация опасная для водной экосистемы в целом.

Повышенное содержание ТМ в воде и донных отложениях определяет вероятность их накопления в водной растительности, которая играет важную роль среди компонентов, составляющих водную экосистему [29]. Аккумулируя различные соединения, в том числе ТМ, водные растения удерживают их в течение всего вегетационного периода до своего отмирания и разложения [30, 31].

Результаты наших исследований показывают заметное влияние мелиорирования по величине накопления ТМ в стебле и листве рдеста пронзеннолистного, отобранных в разных точках водотока (табл. 3).

Таблица 3. Концентрацчи тяжельх металлов в водных pacтениях Potamogeton perfoliatus,мг/кг

Table 3. Concentrations of heavy metals in aquatic plants Potamogeton perfoliatus, $\mathrm{mg} / \mathrm{kg}$

\begin{tabular}{|c|c|c|c|}
\hline $\begin{array}{c}\text { Тяжелые } \\
\text { металлы } \\
\text { Heavy metals }\end{array}$ & $\begin{array}{c}\text { Верхнеe } \\
\text { течение } \\
\text { Upstream }\end{array}$ & $\begin{array}{c}\text { Осушительный } \\
\text { канал } \\
\text { Drainage channel }\end{array}$ & $\begin{array}{c}\text { Нижнее } \\
\text { течение } \\
\text { Downstream }\end{array}$ \\
\hline $\mathrm{Fe}$ & $7940 \pm 100$ & $17010 \pm 130$ & $10730 \pm 99$ \\
\hline $\mathrm{Mn}$ & $281 \pm 50$ & $1149 \pm 63$ & $904 \pm 96$ \\
\hline $\mathrm{Pb}$ & $117 \pm 30$ & $624 \pm 23$ & $429 \pm 41$ \\
\hline $\mathrm{Zn}$ & $3,5 \pm 0,1$ & $11,3 \pm 0,5$ & $9,3 \pm 1,1$ \\
\hline $\mathrm{Cu}$ & $2,6 \pm 0,1$ & $6,4 \pm 0,3$ & $3,9 \pm 0,3$ \\
\hline $\mathrm{Ni}$ & $0,03 \pm 0,001$ & $0,1 \pm 0,02$ & $0,09 \pm 0,01$ \\
\hline
\end{tabular}


Проведенные исследования показали, что по содержанию тяжелых металлов в водных растениях можно выстроить следующий концентрационный ряд: $\mathrm{Fe}>\mathrm{Mn}>\mathrm{Pb}>\mathrm{Zn}>\mathrm{Cu}>\mathrm{Ni}$. Наименьшая аккумуляция TM в растениях найдена в точках отбора проб верхнего течения реки. Наибольшее накопление металлов обнаружено в точках отбора проб непосредственного впадения осушительного канала в реку, содержание $\mathrm{Mn}$ и Рb увеличивается в 4,5-5 раз, Ni и Zn - в 3 раза, a $\mathrm{Fe}$ и $\mathrm{Cu}-2$ раза, по сравнению с верхним течением реки. В нижнем течении реки концентрация железа, свинца и никеля примерно в 1,5-2 раза, а марганца и цинка - в 4-5 раз больше по отношению к верхнему течению. Таким образом, осушительная мелиорация, меняя гидрохимические и гидрологические характеристики водотоков, приводит к увеличению концентраций ТМ в макрофитах.

\section{СПИСОК ЛИТЕРАТУРЫ}

1. Воронов Б.А., Махинов А.Н. Комплексные экспедиционные исследования природной среды бассейна реки Амур // Вестник ДВО РАН. - 2009. - № 3. - С. 3-14.

2. Influence of agrochemical rehabilitation on the heavy metal migration to the water / Yu. Mazhayskiy, O. Chernikova, A. Karpov, O. Miseckaite // AGROFOR International Journal. 2017. - V. 2. - Iss. 1. - P. 83-90. URL: http://doi.org/10.7251/ AGRENG1701083M (дата обращения 02.02.2020).

3. Аминева А.А., Суюндуков Я.Т., Янтурин И.Ш. Миграция тяжелых металлов в водных экосистемах геохимической провинции Зауралья (на примере озера Чебаркуль Республики Башкортостан) // Вестник Оренбургского государственного университета. - 2016. - № 5. - С. 36-40.

4. Зубарев В.А., Мищук С.Н. Изменение концентраций тяжелых металлов почв юга Среднеамурской низменности при длительном сельскохозяйственном использовании // Известия Томского политехнического университета. Инжиниринг георесурсов. 2019. - T. 330. - № 8. - C. 18-26. URL: http://doi.org/ 10.18799/24131830/2019/8/2208 (дата обращения 02.02.2020).

5. Zubarev V.A., Kogan R.M. Ecological conditions of watercouses in the Middle Amur Lowland in the areas of drainage reclamation / Water Resources. - 2017. - V. 44. - № 7. - P. 940-951. URL: http://doi.org/10.1134/S0097807817070144 (дата обращения $02.02 .2020)$.

6. ГОСТ 51592-2000 Вода. Общие требования к отбору проб. М.: Стандартинформ, 2008. -48 с.

7. ГОСТ 17.1.5.01-80 Охрана природы. Гидросфера. Общие требования к отбору проб донных отложений водных объектов для анализа на загрязненность. - М.: Изд-во стандартов, 2002. -7 c.

8. Физико-химические аспекты миграционных процессов тяжелых металлов в природных водных системах / О.А. Давыдова, Е.В. Коровина, Е.С. Ваганова, И.Т. Гусева, Б.А. Красун, М.А. Исаева, Т.Ю. Марцева, В.В. Мулюкова, Е.С. Климов, М.В. Бузаева // Вестник Южно-Уральского государственного университета. Серия: Химия. - 2016. - Т. 8. - № 2. - С. 40-50. URL: http://doi.org/10.14529/chem160205 (дата обращения 02.02.2020)

9. Petrosyan V., Pirumyan G., Perikhanyan Y. Determination of heavy metal background concentration in bottom sediment and risk assessment of sediment pollution by heavy metals in the Hrazdan River (Armenia) // Applied Water Science. - 2019. V. 9. - Iss. 4. - P. 1-9. URL: http://doi.org/10.1007/s13201-0190996-7 (дата обращения 02.02.2020).

10. Нахшина Е.П. Тяжелые металлы в системе «вода - донные отложения» водоемов (обзор) // Гидробиологический журнал. - 1985. - № 2. - С. 80-90.

11. Уваров А.Г. Оценка степени загрязнения тяжелыми металлами реки Москвы и возможность использования макрофитов рода Potamogeton для биомониторинга тяжелых металлов в

\section{Выводы}

1. Под влиянием осушения в поверхностных водах происходит увеличение концентраций растворенных и взвешенных форм тяжелых металлов, в особенности $\mathrm{Fe}$ и $\mathrm{Pb}$, превышающих значения предельно-допустимых концентраций в 3 раза.

2. В донных отложениях происходит накопление тяжелых металлов, однако при изменении химических и гидрологических параметров среды они переходят опять в водоток, являясь источником вторичного загрязнения.

3. Осушительная мелиорация, меняя гидрохимические и гидрологические характеристики водотоков, приводит к увеличению концентраций тяжелых металлов в макрофитах в 2-3 раза.

Исследование выполнено при финансовой поддержке РФФИ в рамках научного проекта № 17-32-01100-ОГН.

реке // Известия Самарского научного центра РАН. - 2015. T. 17. - № 6. - C. 150-158.

12. Фомина А.А., Тихомирова Е.И., Кораблева А.И. Анализ содержания тяжелых металлов в высших водных растениях Волгоградского водохранилища в районе агломерации Саратов-Энгельс // Известия Самарского научного центра Российской академии наук. - 2016. - Т. 18. - № 2 (3). - С. 822-826.

13. Содержание и миграция тяжелых металлов в компонентах экосистем Волгоградского водохранилища / Е.К. Еськов, В.М. Зубкова, Н.Ю. Белозубова, В.П. Болотов // Аграрная наука. - 2015. - № 1. - С. 14-15.

14. Bioremediation of heavy metals from soil and aquatic environment an overview of principles and criteria of fundamental processes / Ruchita Dixit, Wasiullah, Deepti Malaviya, Kuppusamy Pandiyan, U.B. Singh, Asha Sahu, Renu Shukla, B.P. Singh, J.P. Rai, Pawan Kumar Sharma, Harshad Lade, Diby Paul // Sustainability. - 2015. V. 7. - P. 2189-2212. URL: http://doi.org/10.3390/su7022189 (дата обращения 02.02.2020).

15. Трансформация минерального состава донных отложений от истоков к устьям рек / О.Г. Савичев, В.А. Домаренко, Е.В. Перегудина, О.Е. Лепокурова // Известия Томского политехнического университета. Инжиниринг георесурсов. - 2018. T. 329. - № 7.- С. 43-56.

16. Чудаева В.А., Шестеркин В.П., Чудаев О.В. Микроэлементы в поверхностных водах бассейна реки Амур // Водные ресурсы. - 2011. - Т. 38. - № 5. - С. 606-617.

17. Левшина С.И. Распределение железа в поверхностных водах бассейна Среднего и Нижнего Амура // Водные ресурсы. 2012. - T. 39. - № 4. - С. 377-384.

18. Фоновые гидрохимические показатели поверхностных вод бассейна реки Вах Ханты-Мансийского автономного округа Югры / В.А. Пуртов, И.В. Завьялова, Д.А. Селиванова, Н.С. Ремень // Защита окружающей среды в нефтегазовом комплексе. - 2013. - № 4. - С. 31-38.

19. Дударева И.А., Алимова Г.С., Токарева А.Ю. Марганец в воде и донных отложениях нижнего течения реки Иртыш // Успехи современного естествознания. - 2017. - № 8. - С. 70-74.

20. Хайсанова Т.С. Факторы, влияющие на бактериальнохимические процессы переработки сульфидных руд // Записки горного института. - 2019. - № 235. - С. 47-54. URL: http:// doi.org/10.31897/PMI.2019.1.47 (дата обращения 02.02.2020).

21. Elements in water, suspended particulate matter and sediments of the Sava River / J. Vidmar, T. Zuliani, P. Novak, A. Drinčić, J. Ščančar, R. Milačič // Journal of Soils and Sediments. - 2017. V. 17. - Iss. 7. - P. 1917-1927. URL: http://doi.org/10.1007/s11368016-1512-4 (дата обращения 02.02.2020).

22. Fischer E., Constant M.G. Determination of lead complexation in lake water by cathodic stripping voltammetry and ligand competition // Analytica Chimica Acta. - 2001. - V. 432. Iss. 1. - P. 11-20. URL: http://doi.org/10.1016/S00032670(00)01353-2 (дата обращения 02.02.2020). 
23. Янин Е.П. Источники и пути поступления тяжелых металлов в реки сельскохозяйственных районов // Экологическая экспертиза. - 2004. - № 4. - С. 67-90.

24. Potential sources of anthropogenic copper inputs to European agricultural soils / P. Panagos, C. Ballabio, E. Lugato, A. Jones, P. Borrelli, S. Scarpa, A. Orgiazzi, L. Montanarella // Sustainability. - 2018. - V. 10. - P. 2380. URL: https://doi.org/ $10.3390 /$ su10072380 (дата обращения 02.02.2020).

25. Hydrochemical study of water collected at a section of the Lower Volta River (Akuse to Sogakope area), Ghana / E.K. Gampson, V.K. Nartey, A.A. Golow, T.T. Akiti // Applied Water Science. 2014. - V. 4. - Iss. 2. - P. 129-143. URL: http://doi.org/10.1007/ s13201-013-0136-8 (дата обращения 02.02.2020).

26. Косинова И.И., Соколова Т.В. Методологические особенности оценки экологического состояния донных отложений искусственно созданных водных объектов // Вестник ВГУ. Серия: Геология. - 2015. - № 3. - С. 113-121.

27. Edwards C.A. Assessing the effects of environmental pollutants on soil organisms, communities, processes and ecosystems // European Journal of Soil Biology. - 2002. - V. 38. - Iss. 3-4. P. 225-231. URL: http://doi.org/10.1016/S1164-5563(02)01150-0 (дата обращения 02.02.2020).

Информация об авторах
28. Загрязнение донных отложений реки Клязьма тяжелыми металлами и мышьяком в пределах Московской области / Б.И. Корженевский, Г.Ю. Толкачёв, Т.А. Ильина, А. Валиева // Мелиорация и водное хозяйство. - 2019. - № 3. - С. 34-39.

29. Галдеева О.Ф., Козловская О.В., Копнина А.Ю. Экологические аспекты накопления тяжелых металлов в высших водных растениях в процессе фиторемедиации // Самарский научный вестник. - 2018. -T. 7. - № 3 (24). - С. 23-27.

30. Freedman B., Lacoul P. Environmental influences on aquatic plants in freshwater ecosystems // Environmental Reviews. 2006. - V. 14. - № 2. - P. 89-136. URL: http://doi.org/10.1139/A06001 (дата обращения 02.02.2020).

31. Assessment of anthropogenic influence on heavy metals contamination in the aquatic ecosystem components: water, sediment, and fish / M. Safiur Rahman, Narottam Saha, A. Hossain Molla, Sharif M. Al-Reza // Soil and Sediment Contamination: an International Journal. - 2014. - V. 23. - № 4. P. 353-373. DOI: 10.1080/15320383.2014.829025

Поступила 12.03.2020 2.

Зубарев В.A., научный сотрудник, Институт комплексного анализа региональных проблем ДВО РАН. 
UDK 626.80 (571.621)

\title{
CHANGE OF CONCENTRATIONS OF HEAVY METALS IN THE COMPONENTS OF A SMALL RIVER (ON THE EXAMPLE OF DRAINAGE RECLAMATION)
}

\author{
Vitaliy A. Zubarev, \\ Zubarev_1986@mail.ru \\ Institute for the Integrated Analysis of Regional Problems, Far Eastern Branch of the Russian Academy of Sciences, \\ 4, Sholem Aleichem street, Birobidzhan, 679016, Russia.
}

The relevance of the research lies in the need to assess such components of watercourse ecosystem as bottom sediments and aquatic plants that are able to accumulate various pollutants from the catchment area and can serve as indicators of the ecological state of pollution of the surface watercourse.

The aim of the work is an environmental assessment of small rivers of the Middle Amur Lowland under the influence of drainage reclamation according to the content of heavy metals.

Objects: surface water, bottom sediments and aquatic plants susceptible to drainage reclamation.

Methods: filtering water samples through membrane filters with a pore diameter of 0,45 $\mu \mathrm{m}$ for the separate determination of dissolved and suspended forms of heavy metals; sampling of bottom sediments with a Gr-91 rod-type dredger at a depth of $25 \mathrm{~cm}$ from the bedding surface; acid decomposition of samples of bottom sediments and vegetation in the "Mars-6» microwave system, grinding in a "Pulverisette 6» planetary mill, determination of heavy metals by atomic absorption spectrometry on a «Solaar 6M» spectrometer.

Results. In surface waters, there is an increase in gross concentrations of heavy metals, especially iron and lead, exceeding the maximum permissible concentrations by three times. The accumulation of various pollutants takes place in bottom sediments, however, when the chemical and hydrological parameters of the environment change, they again pass into the watercourse, thereby being a source of secondary pollution. The most intense deposition processes were calculated for $\mathrm{Fe}$ (lgK=5,06), $P b$ (lgK=4,76), as well as for $\mathrm{Zn}(\operatorname{lgK}=4,60)$. The average character of sedimentation can be traced for $\mathrm{Mn}$ and $\mathrm{Cu}(\mathrm{IgK}=3,36)$. For $\mathrm{Ni}$, the coefficient has a minimum value $(\mathrm{IgKK}=2,82)$, which indicates metal reverse migration from bottom sediments to water. Under the influence of drainage, an increase in concentration of heavy metals in macrophytes occurs.

\section{Key words:}

Middle Amur lowland, small rivers, aquatic vegetation, heavy metals, bottom sediments, drainage reclamation.

The research was financially supported by the RFBR within the science project no. 17-32-01100-OГH.

\section{REFERENCES}

1. Voronov B.A., Makhinov A.N. Kompleksnye ekspeditsionnye issledovaniya prirodnoy sredy basseyna reki Amur [Complex field works of the environment of the Amur river basin]. Vestnik DVO $R A N, 2009$, vol. 3, pp. 3-14.

2. Mazhayskiy Yu., Chernikova O., Karpov A., Miseckaite O. Influence of agrochemical rehabilitation on the heavy metal migration to the water. AGROFOR International Journal, 2017, vol. 2, no. 1, pp. 83-90. Available at: http://doi.org/10.7251/AGRENG1701083M (accessed 2 February 2020).

3. Amineva A.A., Suyundukov Ya.T., Yanturin I.Sh. Migratsiya tyazhelykh metallov v vodnykh ekosistemakh geokhimicheskoy provintsii Zauralya (na primere ozera Chebarkul Respubliki Bashkortostan) [Heavy metal migration in water ecosystems of geochemical province of Trans Urals (on the example of the lake Chebarkul in the Republic of Bashkortostan)]. Vestnik Orenburgskogo gosudarstvennogo universiteta, 2016, vol. 5, pp. 36-40.

4. Zubarev V.A., Mishchuk S.N Changes in concentration of heavy metals in soils of Middle Amur lowland under conditions of long period of agricultural use. Bulletin of the Tomsk Polytechnic University. Geo Assets Engineering, 2019, vol. 330, no. 8. pp. 18 26. In Rus. Available at: http://doi.org/10.18799/24131830/ 2019/8/2208 (accessed 2 February 2020).

5. Zubarev V.A., Kogan R.M. Ecological conditions of watercouses in the Middle Amur Lowland in the areas of drainage reclamation. Water Resources, 2017, vol. 44, no. 7, pp. 940-951. Available at: http://doi.org/10.1134/S0097807817070144 (accessed 2 February 2020).

6. GOST 51592-2000. Voda. Obshchie trebovaniya $k$ otboru prob [Water. General requirements for sampling]. Moscow, Standartinform Publ., 2008. 48 p.

7. GOST 17.1.5.01-80. Okhrana prirody. Gidrosfera. Obshchie trebovaniya $k$ otboru prob donnykh otlozheniy vodnykh obektov dlya analiza na zagryaznennost [Nature protection. Hydrosphere. General requirements for sampling of bottom sediments of water objects for their pollution analysis]. Moscow, Izdatelstvo standartov Publ., 2002. 7p.

8. Davydova O.A., Korovina E.V., Vaganova E.S., Guseva I.T., Krasun B.A., Isaeva M.A., Marceva T.Yu., Mulyukova V.V., Klimov E.S., Buzaeva M.V. Physical-chemistry aspects of migratory processes of heavy metals in natural aqueous systems. Bulletin of the South Ural State University. Ser. Chemistry, 2016, vol. 8, no. 2, pp. 40-50. In Rus. Available at: http://doi.org/10.14529/ chem160205 (accessed 2 February 2020).

9. Petrosyan V., Pirumyan G., Perikhanyan Y. Determination of heavy metal background concentration in bottom sediment and risk assessment of sediment pollution by heavy metals in the Hrazdan River (Armenia). Applied Water Science, 2019, vol. 9, no. 4, pp. 1-9. Available at: http://doi.org/10.1007/s13201-0190996-7 (accessed 2 February 2020)

10. Nakhshina E.P. Tyazhelye metally v sisteme «voda - donnye otlozheniya» vodoemov (obzor) [Heavy metals in the «waterbottom sediments» system of water bodies (review)]. Gidrobiologicheskiy zhurnal, 1985, vol. 2, pp. 80-90.

11. Uvarov A.G. Estimation the extent pollution by heavy metals the Moscow river, possibility of use the Potamogeton macrophytes for biomonitoring the heavy metals in the river. Izvestia of Samara Scientific Center of the Russian Academy of Sciences, 2015, vol. 17, no. 6, pp. 150-158. In Rus.

12. Fomina A.A., Tihomirova E.I., Korableva A.I. The analysis of heavy metals content in the higher aquatic plants of volgograd water storage basin around Saratov-Engels agglomeration. Izvestia of Samara Scientific Center of the Russian Academy of Sciences, 2016, vol. 18, no. 2 (3), pp. 822-826. In Rus.

13. Eskov E.K., Zubkova V.M., Belozubova N.Yu., Bolotov V.P. Heavy metal content and migration in the components of ecosystems of Volgograd reservoir basin. Agrarnaya nauka, 2015, vol. 1, pp. 14-15. In Rus. 
14. Ruchita Dixit, Wasiullah, Deepti Malaviya, Kuppusamy Pandiyan, Udai B. Singh, Asha Sahu, Renu Shukla, Bhanu P. Singh, Jai P. Rai, Pawan Kumar Sharma, Harshad Lade, Diby Paul. Bioremediation of heavy metals from soil and aquatic environment: an overview of principles and criteria of fundamental processes. Sustainability, 2015, vol. 7, pp. 2189-2212. Available at: http://doi.org/10.3390/ su7022189 (accessed 2 February 2020)

15. Savichev O.G., Domarenko V.A., Peregudina E.V., Lepokurova O.E. Transformation of mineral composition of river sediments from sources to mouth of rivers. Bulletin of the Tomsk Polytechnic University. Geo Assets Engineering, 2018, vol. 329, no. 7, pp. 43-56. In Rus.

16. Chudaeva V.A., Shesterkin V.P., Chudaev O.V. Trace elements in surface water in Amur River basin. Water Resources, 2011, vol. 38 no. 5, pp. 650-661. Available at: http://doi.org/10.1134/ S0097807811050034 (accessed 2 February 2020).

17. Levshina S.I. Iron distribution in surface waters in the Middle and Lower Amur basin. Water Resources, 2012, vol. 39, no. 4, pp. 375-383. Available at: http://doi.org/10.1134/S0097807812040082 (accessed 2 February 2020).

18. Purtov V.A., Zavyalova I.V., Selivanova D.A., Remen N.S Background hydrochemical indicies of surface waters of the basin of the river Vakh in Khanty-Mansiysk autonomous okrug - Yugra. Zashchita okruzhayushchej sredy v neftegazovom komplekse, 2013 vol. 4, pp. 31-38. In Rus.

19. Dudareva I.A., Alimova G.S., Tokareva A.Yu. Marganets v vode donnykh otlozheniyakh nizhnego techeniya reki Irtysh [Manganese in water and bottom sediments of the lower reaches of the Irtysh River]. Uspekhi sovremennogo estestvoznaniya, 2017, vol. 8, pp. 70-74

20. Khainasova T.S. Factors affecting bacterial and chemica processes of sulphide ores processing. Journal of Mining Institute, 2019, vol. 235, pp. 47-54. In Rus. Available at: http://doi.org/10.31897/ PMI.2019.1.47 (accessed 2 February 2020).

21. Vidmar J., Zuliani T., Novak P., Drinčić A., Ščančar J., Milačič R. Elements in water, suspended particulate matter and sediments of the Sava River. Journal of Soils and Sediments, 2017, vol. 17, no. 7, pp. 1917-1927. Available at: http://doi.org/10.1007/ s11368-016-1512-4 (accessed 2 February 2020).

22. Fischer E., Constant M.G. Determination of lead complexation in lake water by cathodic stripping voltammetry and ligand competition. Analytica Chimica Acta, 2001, vol. 432, no. 1, pp. 11-20. Available at: http://doi.org/10.1016/S00032670(00)01353-2 (accessed 2 February 2020).
23. Yanin E.P. Istochniki i puti postupleniya tyazhelykh metallov v reki selskokhozyaystvennykh rayonov [Sources and routes of entry of heavy metals into agricultural rivers]. Ekologicheskaya ekspertiza, 2004, vol. 4. pp. 67-90.

24. Panagos P., Ballabio C., Lugato E., Jones A., Borrelli P., Scarpa S. Orgiazzi A., Montanarella L. Potential sources of anthropogenic copper inputs to European agricultural soils. Sustainability, 2018, vol. 10, p. 2380. Available at: https://doi.org/10.3390/su10072380 (accessed 2 February 2020).

25. Gampson E.K., Nartey V.K., Golow A.A., Akiti T.T. Hydrochemical study of water collected at a section of the Lower Volta River (Akuse to Sogakope area), Ghana. Applied Water Science, 2014, vol. 4, no. 2, pp. 129-143. Available at: http://doi.org/ 10.1007/s13201-013-0136-8 (accessed 2 February 2020).

26. Edwards C.A. Assessing the effects of environmental pollutants on soil organisms, communities, processes and ecosystems. European Journal of Soil Biology, 2002, vol. 38, no. 3-4, pp. 225-231. Available at: http://doi.org/10.1016/S1164-5563(02)01150-0 (accessed 2 February 2020).

27. Kosinova I.I., Sokolova T.V. Methodological features of assessing the ecological state bottom sediments of artificial water objects. Vestnik VGU. Seriya: Geologiya, 2015, vol. 3, pp. 113-121. In Rus.

28. Korzhenevskiy B.I., Tolkachev G.Yu., Ilina T.A., Valieva A. Pollution of bottom sediments of the river Klyazma with heavy metals and arcenic within Moscow region. Melioratsiya $i$ vodnoe khozyaystvo, 2019, vol. 3, pp. 34-39. In Rus.

29. Freedman B., Lacoul P. Environmental influences on aquatic plants in freshwater ecosystems. Environmental Reviews, 2006, vol. 14, no. 2. pp. 89-136. Available at: http://doi.org/10.1139/ A06-001 (accessed 2 February 2020).

30. Galdeeva O.F., Kozlovskaya O.V., Kopnina A.Yu. Ecological aspects of heavy metal storage aquatic higher plants in phytoremediation. Samarskiy nauchny vestnik, 2018, vol. 7, no. 3 (24), pp. 23-27. In Rus.

31. Safiur Rahman M., Narottam Saha, Hossain Molla A., Sharif M. Al-Reza Assessment of Anthropogenic Influence on Heavy Metals Contamination in the Aquatic Ecosystem Components: Water, Sediment, and Fish. Soil and Sediment Contamination: An International Journal, 2014, vol. 23, no. 4, pp. 353-373. DOI: $10.1080 / 15320383.2014 .829025$.

Received: 12 March 2020.

\section{Information about the authors}

Vitaliy A. Zubarev, researcher, Institute for the Integrated Analysis of Regional Problems, Far Eastern Branch of the Russian Academy of Sciences. 